Computerized Virtual Reality Simulation in Preclinical Dentistry: Can a Computerized Simulator Replace the Conventional Phantom Heads and Human Instruction?

\title{
Plessas, Anastasios
}

http://hdl.handle.net/10026.1/11267

$10.1097 / \operatorname{sih} .0000000000000250$

Simulation in Healthcare: The Journal of the Society for Simulation in Healthcare Ovid Technologies (Wolters Kluwer Health)

All content in PEARL is protected by copyright law. Author manuscripts are made available in accordance with publisher policies. Please cite only the published version using the details provided on the item record or document. In the absence of an open licence (e.g. Creative Commons), permissions for further reuse of content should be sought from the publisher or author. 


\section{TITLE PAGE}

5

6 Title: Computerized Virtual Reality Simulation in Preclinical Dentistry.

7 Can a computerized simulator replace the conventional phantom heads and human 8 instruction?

Author: Anastasios Plessas MSc

14

(Qualifications: DipDS, MSc, DipPCD RCSI, MFGDP(UK), FHEA) NIHR Academic and Clinical Fellow in General Dental Practice, Peninsula Dental 16 School, Plymouth University

Correspondence: Anastasios Plessas, C507, Portland Square, Peninsula Dental 21 School, Plymouth University, PL4 8AA,

E-mail: anastasios.plessas@plymouth.ac.uk,

Tel: $+44(0) 1752286841$

24

Word Count: 2.749

27 Conflict of interest: NONE 


\section{Summary Statement}

In preclinical dental education, the acquisition of clinical, technical skills and the

37 transfer of these skills to the clinic are paramount. Phantom heads provide an 38 efficient way to teach preclinical students dental procedures safely while increasing 39 their dexterity skills considerably. Modern computerized phantom head training units 40 incorporate features of virtual reality technology and the ability to offer concurrent 41 augmented feedback. The aim of this review was to examine and evaluate the dental 42 literature for evidence supporting their use and discuss the role of augmented 43 feedback versus the facilitator's instruction. Adjunctive training in these units seems 44 to enhance student's learning and skill acquisition and reduce the required faculty supervision time. However, the virtual augmented feedback cannot be used as the sole method of feedback, and the facilitator's input is still critical. Well-powered

47 longitudinal randomized trials exploring the impact of these units on student's clinical 48 performance and issues of cost-effectiveness are warranted.

Key Words: dental education, faculty, simulation training 


\section{INTRODUCTION}

55 Operative dentistry is a demanding area of clinical education ${ }^{1}$. The development of clinical competence requires the assimilation of large amounts of knowledge

57 combined with the acquisition of clinical skills and problem-solving ability ${ }^{1}$. One of 58 the most essential clinical skills in operative dentistry is preparing and restoring 59 carious teeth. The student needs to comprehend the concepts of the procedure and develop the fine motor skills to perform it ${ }^{2}$. The acquisition of clinical, technical skills and the transfer of these skills to the clinic, where real patients are treated, is of paramount importance ${ }^{3}$. This can be achieved by vigorous training on phantom heads ${ }^{4}$. Phantom heads provide an efficient way to teach preclinical students dental procedures safely while increasing their psychomotor skills considerably ${ }^{4,5}$.

Phantom heads have been the cornerstone of learning in operative dentistry worldwide since their introduction in $1894^{4}$. The phantom head is affixed to a dental operating unit with a torso, in a manner that allows adjustment of position to allow the students to work in a seated position as they would in a clinical setting ${ }^{3}$. The heads also have a rubber sheet which provides an approximation of the patient's cheeks and mouth opening (Figure 1) ${ }^{3}$.

71 Phantom heads replicate the real-life clinical environment including positioning of the operator and the patient, performing dental procedures with an assistant, and infection control procedures ${ }^{3}$. Traditionally in preclinical simulation training, the students are shown models, diagrams, and pictures and are asked to repeatedly perform dental procedures on plastic phantom head teeth ${ }^{6}$. The learners receive verbal feedback by a 
77 faculty instructor when they have completed all or a portion of a cavity or 78 tooth preparation task (Figure 2) ${ }^{7}$.

79 In recent years, technological advances have facilitated the incorporation of virtual reality simulation technology in preclinical operative dental education. Virtual reality simulators provide the opportunity for integrating clinical case scenarios in the operative teaching environment and also facilitating the tactile diagnostic skills by utilizing haptic technology ${ }^{1}$. To date, two types of computerized virtual reality dental simulators are available: mannequin-based simulators on which certain dental procedures can be performed using real dental instruments (e.g. DentSim TM and Image Guided Implantology IGI both produced by the DenX, Ltd.) and haptic-based simulators which employ a haptic device and virtual models of a human tooth or mouth as a platform for facilitating the practise of dental procedures (e.g PHANToM TM, Virtual Reality Dental Training System VRDTS, lowa Dental Surgical Simulator, HapTEL, VirDenT \& Moog Simodont Dental Trainer) ${ }^{1,5,6}$.

The mannequin-based computerized simulators combine the benefits of training on a traditional phantom head operating unit ${ }^{3}$, with the benefits of virtual reality simulation ${ }^{8}$. These units were the focus of the present review; hereinafter referred to as CVRS.

A computerized phantom head dental simulator which incorporates virtual reality features and provides augmented visual feedback is the DentSim Unit ${ }^{1}$. It has been available since 1997 and has been used and evaluated in Dental Institutions in the U.S., Europe, and Asia 1, 6, 9-11. The unit includes a phantom head, a dental handpiece, a light source, an infrared camera and two computers. The phantom head and handpiece contain infrared emitters which allow the infrared camera to 
101 phantom head, the software formulates a virtual three-dimensional representation of

102 the preparation in progress which is presented on the computer screen (Figure 3) ${ }^{6,8}$.

103 The student's cavity preparation can be compared to the ideal cavity preparation by 104 overlaying the two virtual reality images at any time during the procedure ${ }^{6,8,12}$. 105 Procedural errors are audio-signalled as they are made and the generated error 106 messages can be viewed immediately ${ }^{12}$. A final evaluation report and a list of errors 107 become available at the end of the procedure ${ }^{6,12}$. The virtual environment is 108 enhanced with complete patient records including examination notes and 109 radiographs which provide a more realistic environment, bringing the technical tasks 110 into a clinical context, during the simulation training ${ }^{12}$.

111 This aim of this review was to examine and evaluate the existing body of literature on 112 the use of the CVRS in preclinical dental education. The impact on student's 113 performance and learning experience, as well as the role of the faculty instruction 114 versus the augmented visual feedback provided by these units, in the clinical skills 115 acquisition simulation training, is discussed.

\section{METHODS}

117 A search of the literature was performed searching the following databases via 118 EBSCO: Medline, British Educational Index, and ERIC. The search terms used and 119 the search strategy can be found in Table 1. Papers in which the CVRS were discussed in terms of preclinical dental education were included. Studies using CVRS in postgraduate dental education as well studies using haptic technology 122 simulation systems were excluded. Only studies in the English language were 123 considered for inclusion. Finally, no limits for study design were applied. 
124 The citations retrieved from the above search (79) were inserted into the reference management software Endnote X7.4. The titles and abstracts were screened for relevance. The potentially relevant papers (33) were accessed and read in full-text.

127 The selection process of the included studies (16) and the reasons for exclusion are 128 depicted in the PRISMA flowchart (Figure 4).

\section{RESULTS}

\section{Impact on student performance}

131 From the 79 articles retrieved, 16 were deemed relevant and were included in this review. From these, five prospective experimental studies assessed the students' performance in cavity preparation after additional training on the CVRS. The main characteristics and results of these studies can be found in Table 2. Concerning the quality of tooth preparations, most of the studies found no significant differences between those who trained solely on conventional phantom heads versus those who had been exposed adjunctively to the CVRS

2, 13-15. Conversely, Kikuchi demonstrated that students using the CVRS units performed better quality crown preparations than those who did not ${ }^{9}$. Similarly, when first-year dental students received eight hours of adjunctive computerized dental simulation training, although they performed better early in the study, their clinical performance did not differ as assessed by the final practical examination ${ }^{12}$. As the retention and transferability of skill and knowledge are concerned, several studies found no significant differences in final practical exam scores ${ }^{12,16,17}$. LeBlanc et al. did not identify any marked differences in the final exam scores but observed a more significant improvement between the first and final assessment scores for the CVRS group ${ }^{2}$. In contrast, 147 Magio et al. suggested that the introduction of the CVRS in preclinical dental training 
resulted in a reduction in the course remediation rate and reduction of the course

149 failure rates by more than a half ${ }^{18,19}$.

\section{Time efficiency}

151 In an experimental study at the University of Pennsylvania, the students who 152 received CVRS training showed a higher efficiency in cavity preparations than the 153 students who trained on the traditional phantom heads ${ }^{16}$. Namely, they prepared significantly more teeth per hour (3.8 versus 1.6) and used more teeth (average of 11.71 versus 6.57 for control, $p=0.02$ ) during their practising session ${ }^{16}$. Similarly, training sessions with CVRS shortened the crown preparation time performed by fifth-year dental students at Tokyo Medical and Dental University ${ }^{9}$. Besides, virtual reality simulators appear to reduce the required instruction and supervision time by faculty members of staff ${ }^{16}$. Jasinevicius et al. demonstrated that students who were trained on conventional simulators received five times more instructional time from faculty than students who were trained on virtual reality ones. However, there were no statistically significant differences in the quality of the preparations despite the additional instructional time ${ }^{13}$.

\section{Student learning experience}

Several studies have surveyed dental students about their preferences over conventional or virtual reality simulation. CVRS training seems to be rated rather positively by the students. The majority (87.3\%) of first-year students at Tennessee Dental school working with CVRS found the experience to be "very interesting" or "interesting" 11. Amongst the positive features of virtual reality simulators, as perceived by dental students, were the positive impact on improving their manual 
171 and motor skills ${ }^{16}$, the increased speed and number of preparations ${ }^{10,16}$, the access

172 to feedback ${ }^{14}$, the ability for the student to monitor their own work without

173 involvement of a supervisor ${ }^{10,14}$, the preparation for assessment, the consistency of

174 evaluation ${ }^{14,15}$ and the allowance for self-paced learning ${ }^{10,14}$. Students criticized

175 the CVRS for excessive feedback, lack of personal contact and technical difficulties

176 with hardware ${ }^{14,15}$. Also, students agreed that virtual reality simulators could not

177 fully replace the conventional phantom heads and the combination of the two is the

178 most preferable and effective way of learning ${ }^{14,15}$. On the other hand, students

179 found that the feedback and supervision by faculty facilitators can be inconsistent, 180 and supervisors can be too busy, but it increases their confidence in cavity 181 preparations ${ }^{14,15}$.

\section{Feedback}

As far as quality and effectiveness of instruction and feedback is concerned, several studies have suggested that the virtual reality simulator could not be accepted as the sole form of feedback and evaluation the students should be exposed to. Namely, Urbankova et al. concluded that CVRS augmented feedback cannot replace human instruction ${ }^{12}$. Quin et al. suggested that CVRS is not appropriate as a sole method of feedback and evaluation for novice dental students ${ }^{14,15}$. This statement agrees with a later study in which sole CVRS feedback was not found beneficial, as the retention and transfer test scores between students who used CVRS versus conventional phantom heads did not differ significantly ${ }^{17}$. By the same token, Wierinck et al. have suggested that alternating virtual reality with human instruction and feedback can result in positive learning outcomes ${ }^{7}$. 
196 The role of simulation has been recognized as an important aspect of training in

197 healthcare which supports and improves patient safety ${ }^{20}$. Technology-enhanced 198 simulation, including virtual reality training, has been associated with positive outcomes for healthcare trainee's knowledge and skills ${ }^{21}$. The use of virtual reality simulators for the training of novice surgical trainees has been supported by a number of systematic reviews ${ }^{22-26}$. In laparoscopic surgery, it has been shown to result in a significant reduction in operating time and procedural errors while improving the trainees' performance scores ${ }^{23,24}$. Besides, two recent systematic reviews by the Cochrane Collaboration, in the fields of endoscopy and ENT surgery, suggested that virtual reality simulation can be used to supplement traditional surgical training for medical students and surgical trainees with little or no surgical experience ${ }^{25,26}$. Nonetheless, the authors concluded that virtual reality training allows trainees to develop technical skills at least as good as those achieved through conventional training 25 .

210 Similarly, adjunctive training on the dental CVRS has the potential to improve student's clinical performance and enhance their practical examination scores ${ }^{9,12,15,}$ 17. The augmented feedback through visual cues can facilitate proper eye-hand coordination, and reduce the number of procedural errors ${ }^{12}$. Confronting the students with their own errors as they are made, allows them to visually inspect their work compared to an ideal model ${ }^{14,17}$ and instantaneously rectify it, which can potentially increase learning efficiency and skill development ${ }^{12}$. Noteworthily, although students seemed to perform better early after the CVRS training, their clinical performance in final exams did not differ from that of the students who trained 
219 solely on traditional phantom-head units ${ }^{12,16,17}$. The fact that the amount of transfer

220 from one task onto another depends on the similarity of the neural processing 221 demands, underlying motor execution, may offer an explanation ${ }^{17}$. Besides, the 222 transferability of skills from one context to another is not an uncommon finding in 223 healthcare simulation. Namely, studies in the fields of bronchoscopy, endoscopy and 224 laparoscopic surgery have shown that skills acquired using virtual-reality simulation will transfer to the operating room ${ }^{27-29}$.

226 Nonetheless, with the expansion of the dental curricular content, the effective use of student's time has become an increasing necessity ${ }^{14}$. CVRS training has shown to improve students' efficiency in teeth preparations ${ }^{9,16}$ and reduce the required time for faculty instruction and supervision ${ }^{13}$. Hence, the faculty instructors' time can be utilized in teaching the students crucial non-procedural skills such as patient management, ethics, and teamwork. Sharing their expertise and experiences in the transition of a student from novice to clinician remains critical ${ }^{7,12}$.

233 The unsuitability of the use of CVRS feedback as the sole method of feedback and evaluation for novice students is a consistent criticism amongst the included studies 7, 14, 15, 17. Although CVRS appear to be a reliable method for monitoring technical progress, addressing the issue of lack of reproducibility amongst assessors ${ }^{15}$; they cannot be used as a substitute for expert feedback. It has been suggested that the extensively detailed and sometimes complex computer feedback can be discouraging and overwhelming, especially for the inexperienced students 13,17 . Appropriate faculty input will reinforce learned theoretical concepts and will provide

241 the students with insight into the weaknesses of their performance ${ }^{2,14}$. Contextual 242 learning will enable the students to achieve a deeper understanding of theoretical 
concepts and the impact of any procedural errors (e.g. the biological, clinical, and medico-legal implications of damaging an adjacent tooth or unnecessarily preparing a rather deep cavity).

In a modern preclinical environment, students will reflect on the feedback received by the simulator, the facilitator or both. CVRS can provide the student with continuous (100\%) augmented feedback or they can be set to provide feedback less frequently or none at all. In traditional phantom head preclinical courses, the supervisors offer feedback at the end of critical parts of the procedure and the end of the task. Usually, the ratio of supervisors to students does not permit every student to receive constant feedback and instruction during the dental procedure. According to Wierinck et al. continuous (100\%) CVRS feedback during the task did not offer any additional benefit over intermittent ( $66 \%$ of the time) feedback ${ }^{7}$. Nonetheless, a recent meta-analysis suggested that terminal feedback appears more effective than concurrent feedback for novice learners' skill retention ${ }^{30}$. The mechanism by which feedback may be operating is in line with the guidance hypothesis ${ }^{31}$ and to some extent, the cognitive load theory ${ }^{32}$.

The guidance hypothesis suggests that constant feedback from an instructor during each practice attempt (concurrent feedback) may lead to an over-reliance on the feedback such that when feedback is withdrawn, the learner's performance declines 30, 31 . Reduced frequency of instruction may, therefore, enhance motor skill learning and detection of errors ${ }^{33}$. According to the cognitive load theory, feedback provided during a procedural skills session could influence cognitive load, either increasing it by providing 'information-overload,' or decreasing it by structuring the task so that it 
266 is better understood ${ }^{30,32}$. Thus, it is plausible that continuous feedback may

267 cognitively overload the learner and hinder their learning ${ }^{30}$.

268 The included studies assessed the suitability and effectiveness of the CVRS units as an adjunctive training tool for novice dental students. These units can also act as a valid and reliable screening device to capture expert performance ${ }^{8}$. Wierinck et.al suggested that the DentSim unit can distinguish different levels of excellence in performance (expert versus novice) ${ }^{8}$. On that ground, CVRS may be used in other areas such as continuing dental education, continued competency of practitioners, clinical board exams and remediation of impaired practitioners ${ }^{6}$. Future research will be needed to explore the feasibility of CVRS in these areas. Furthermore, evidence for the long-term effect of CVRS training on the students' clinical performance and competence as well as data regarding the cost-effectiveness of these devices is currently lacking. Future studies should conform to the extended CONSORT and STROBE reporting guidelines for healthcare simulation research ${ }^{20}$, to ensure complete reporting and transparency in the research conduct ${ }^{20,34}$.

\section{CONCLUSION}

282 The existing body of evidence suggests that combining and alternating the traditional and pioneering simulation methods and feedback may be of benefit to the learners. However, there is insufficient evidence to advise for or against the use of computerized virtual reality simulators as a replacement of the traditional phantom heads and human instruction. Virtual reality simulation may enable a better understanding among learners in a more diverse learning environment and augment rather than replace existing teaching methods that work well such as faculty instruction and feedback. Incorporating such a technology in the dental curriculum 
can add a substantial expense nevertheless to a dental faculty's budget. Welldesigned and adequately powered long-term prospective studies exploring matters of student performance, learning outcomes, and cost effectiveness are warranted.

\section{ACKNOWLEDGMENTS}

295 The author would like to thank the reviewers for their thoughtful comments which 296 substantially improved the quality of this review. Also, the author would like to thank 297 Mr Lloyd Russell (Digital marketing, Plymouth University, England UK) for kindly 298 offering the images appearing in Figure 1 and 2 and Professor Els Wierinck (KU 299 Leuven - Department of Oral Health Sciences, University Hospitals Leuven, Belgium) 300 for offering the DentSim images appearing in Figure 3. The author is an NIHR 301 (National Institute for Health Research) funded Academic Clinical Fellow at 302 Peninsula Dental School (Plymouth University). 


\section{REFERENCES}

319 1. Duta M AC, Bogdan CM, Popovici DM, Ionescu N, Nuca Cl: An Overview of Virtual 320 and Augmented Reality in Dental Education. Oral Health Dent Manag. 2011; 10:42-9.

321 2. LeBlanc VR, Urbankova A, Hadavi F, Lichtenthal RM: A preliminary study in using 322 virtual reality to train dental students. J Dent Educ. 2004; 68:378-83.

323 3. Suvinen TI, Messer LB, Franco E: Clinical simulation in teaching preclinical dentistry. 324 Eur J Dent Educ. 1998; 2:25-32.

325 4. Fugill M: Defining the purpose of phantom head. Eur J Dent Educ. 2013; 17:e1-4.

326 5. Kapoor S, Arora P, Kapoor V, Jayachandran M, Tiwari M: Haptics - touchfeedback 327 technology widening the horizon of medicine. J Clin Diagn Res. 2014; 8:294-9.

328 6. Buchanan JA: Use of simulation technology in dental education. J Dent Educ. 2001; 329 65:1225-31.

330 7. Wierinck E, Puttemans V, van Steenberghe D: Effect of reducing frequency of 331 augmented feedback on manual dexterity training and its retention. J Dent. 2006; 34:641-7.

332 8. Wierinck ER, Puttemans V, Swinnen SP, van Steenberghe D: Expert performance on 333 a virtual reality simulation system. J Dent Educ. 2007; 71:759-66.

3349 9. Kikuchi $\mathrm{H}$, Ikeda M, Araki K: Evaluation of a virtual reality simulation system for 335 porcelain fused to metal crown preparation at Tokyo Medical and Dental University. J Dent 336 Educ. 2013; 77:782-92.

337 10. Rees JS, Jenkins SM, James T, Dummer PM, Bryant S, Hayes SJ, Oliver S, Stone 338 D, Fenton C: An initial evaluation of virtual reality simulation in teaching pre-clinical operative 339 dentistry in a UK setting. Eur J Prosthodont Restor Dent. 2007; 15:89-92.

340 11. Welk A, Maggio MP, Simon JF, Scarbecz M, Harrison JA, Wicks RA, Gilpatrick RO: 341 Computer-assisted learning and simulation lab with 40 DentSim units. Int $\mathrm{J}$ Comput Dent. 342 2008; 11:17-40.

343 12. Urbankova A: Impact of computerized dental simulation training on preclinical 344 operative dentistry examination scores. J Dent Educ. 2010; 74:402-9.

345 13. Jasinevicius TR, Landers M, Nelson S, Urbankova A: An evaluation of two dental 346 simulation systems: virtual reality versus contemporary non-computer-assisted. J Dent Educ. 347 2004; 68:1151-62. 
14. Quinn F, Keogh P, McDonald A, Hussey D: A study comparing the effectiveness of conventional training and virtual reality simulation in the skills acquisition of junior dental students. Eur J Dent Educ. 2003; 7:164-9.

15. Quinn F, Keogh P, McDonald A, Hussey D: A pilot study comparing the effectiveness of conventional training and virtual reality simulation in the skills acquisition of junior dental students. Eur J Dent Educ. 2003; 7:13-9.

16. Buchanan JA: Experience with virtual reality-based technology in teaching restorative dental procedures. J Dent Educ. 2004; 68:1258-65.

17. Wierinck E, Puttemans V, Swinnen S, van Steenberghe D: Effect of augmented visual feedback from a virtual reality simulation system on manual dexterity training. Eur $\mathrm{J}$ Dent Educ. 2005; 9:10-6.

18. Maggio MP BJ, Berthold P, Gottlieb R: Curriculum Changes in Preclinical Laboratory Education with Virtual Reality-Based Technology Training. J Dent Educ. 2005; 69:160. 19. Maggio MP BJ, Berthold P, Gottlieb R: Virtual Reality-Based Technology (VRBT) Training Positively Enhances Performance on Preclinical Practical Examinations. J Dent Educ. 2005; 69:161.

20. Cheng A, Kessler D, Mackinnon R, Chang TP, Nadkarni VM, Hunt EA, Duval-Arnould J, Lin Y, Cook DA, Pusic M, Hui J, Moher D, Egger M, Auerbach M: Reporting Guidelines for Health Care Simulation Research: Extensions to the CONSORT and STROBE Statements. Simul Healthc. 2016; 11:238-48.

21. Cook DA, Hatala R, Brydges R, et al.: Technology-enhanced simulation for health professions education: A systematic review and meta-analysis. JAMA. 2011; 306:978-88.

22. Larsen CR, Oestergaard J, Ottesen BS, Soerensen JL: The efficacy of virtual reality simulation training in laparoscopy: a systematic review of randomized trials. Acta Obstet Gynecol Scand. 2012; 91:1015-28.

23. Gurusamy K, Aggarwal R, Palanivelu L, Davidson BR: Systematic review of randomized controlled trials on the effectiveness of virtual reality training for laparoscopic surgery. Br J Surg. 2008; 95:1088-97.

24. Ikonen TS, Antikainen T, Silvennoinen M, Isojarvi J, Makinen E, Scheinin TM: Virtual reality simulator training of laparoscopic cholecystectomies - a systematic review. Scand J Surg. 2012; 101:5-12.

25. Piromchai P, Avery A, Laopaiboon M, Kennedy G, O'Leary S: Virtual reality training for improving the skills needed for performing surgery of the ear, nose or throat. Cochrane Database Syst Rev. 2015:Cd010198. 
26. Walsh CM, Sherlock ME, Ling SC, Carnahan H: Virtual reality simulation training for health professions trainees in gastrointestinal endoscopy. Cochrane Database Syst Rev. 2012:Cd008237.

27. Palter VN, Grantcharov TP: Virtual reality in surgical skills training. Surg Clin North Am. 2010; 90:605-17.

28. Dawe SR, Windsor JA, Broeders JA, Cregan PC, Hewett PJ, Maddern GJ: A systematic review of surgical skills transfer after simulation-based training: laparoscopic cholecystectomy and endoscopy. Ann Surg. 2014; 259:236-48.

29. Kennedy CC, Maldonado F, Cook DA: Simulation-based bronchoscopy training: systematic review and meta-analysis. Chest. 2013; 144:183-92.

30. Hatala R, Cook D, Zendejas B, Hamstra S, Brydges R: Feedback for simulationbased procedural skills training: a meta-analysis and critical narrative synthesis. Adv Health Sci Educ. 2014; 19:251-72.

31. Salmoni AW, Schmidt RA, Walter CB: Knowledge of results and motor learning: a review and critical reappraisal. Psychol Bull. 1984; 95:355-86.

32. Van Merriënboer JJG, Sweller J: Cognitive Load Theory and Complex Learning: Recent Developments and Future Directions. Educ Psychol Rev. 2005; 17:147-77.

33. Winstein CJ, \& Schmidt, R. A. : Reduced frequency of knowledge of results enhances motor skill learning. J Exp Psychol Learn Mem Cogn. 1990; 16:677-91.

34. Sevdalis N, Nestel D, Kardong-Edgren S, Gaba DM: A Joint Leap into a Future of High-Quality Simulation Research-Standardizing the Reporting of Simulation Science. Simul Healthc. 2016; 11:236-7.

.

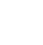

8

7

8

8

11

.

2

(1)


Table and Figure Legends

417

418 Table 1: Search strategy

419 Table 2: Studies comparing student's performance (CVRS versus traditional 420 phantom heads)

421

422

423

424

425

426

427

428

429

430

431

432

433

434

435

436

437

438

439

440

441 
$444 \quad$ Figure Legends

445

446 Figure 1. Phantom head dental simulator unit. Image courtesy of Plymouth 447 University, Peninsula School of Medicine and Dentistry.

448 Figure 2. Traditional dental simulation training and faculty instruction. Images 449 courtesy of Plymouth University Peninsula School of Medicine and Dentistry.

450 Figure 3. CVRS training interface for cavity preparation (DentSim ${ }^{\mathrm{TM}}$ ). Images 451 courtesy of Professor Els Wierinck, KU Leuven - Department of Oral Health 452 Sciences, University Hospitals Leuven, Belgium.

453 Figure 4. Flowchart. Study selection process.

454

455

456

457

458

459

460

461 